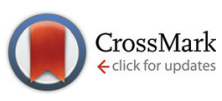

Cite this: Dalton Trans., 2014, 43 16133

Received 16th July 2014, Accepted 18th September 2014

DOI: $10.1039 / c 4 d t 02162 b$

www.rsc.org/dalton

\title{
Structural limitations for optimizing garnet-type solid electrolytes: a perspective
}

\begin{abstract}
Wolfgang G. Zeier*
Lithium ion batteries exhibit the highest energy densities of all battery types and are therefore an important technology for energy storage in every day life. Today's commercially available batteries employ organic polymer lithium conducting electrolytes, leading to multiple challenges and safety issues such as poor chemical stability, leakage and flammability. The next generation lithium ion batteries, namely all solid-state batteries, can overcome these limitations through employing a ceramic $\mathrm{Li}^{+}$conducting electrolyte. In the past decade, there has been a major focus on the structural and ionic transport properties of lithium-conducting garnets, and the extensive research efforts have led to a thorough understanding of the structure-property relationships in this class of materials. However, further improvement seems difficult due to structural limitations. The purpose of this Perspective article is to provide a brief structural overview of $\mathrm{Li}$ conducting garnets and the structural influence on the optimization of Li-ionic conductivities.
\end{abstract}

\section{Introduction}

The growing interest in renewable energy sources has led to a high demand for better and cheaper energy storage solutions,

Department of Applied Physics and Material Science, California Institute of Technology, 1200 E. California Blvd., Pasadena, CA 91125, USA.

E-mail: zeier@caltech.edu

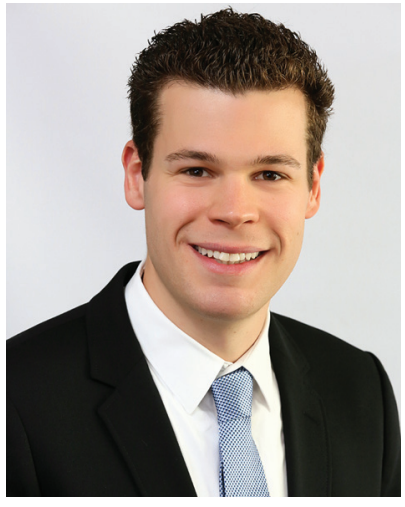

Wolfgang G. Zeier.
In 2013, Wolfgang Zeier received his PhD from the Johannes Gutenberg University in Mainz, Germany. His graduate work, under the supervision of Prof. $\mathrm{Dr}$ Wolfgang Tremel and $\mathrm{Dr}$ G. Jeffrey Snyder, focused on the thermoelectric transport properties of quaternary selenides and Zintl phases. Subsequently, he joined Prof. Brent Melot at the University of Southern California for a one-year postdoctoral position with a research focus on Li-conducting solid electrolytes. Currently, Dr Zeier is a postdoctoral scholar at the California Institute of Technology. His research interests encompass the fundamental structure-to-property relationships of solids, with a strong focus on thermoelectric materials and ionic conductors. like battery systems and supercapacitors. This necessity for high power and high energy density batteries has promoted a growing interest in lithium ion conducting solid electrolytes as a possible replacement of the organic electrolyte in all solidstate lithium ion batteries. This next-generation technology exhibits certain advantages like improved safety, and higher open circuit voltages are also possible. ${ }^{1-3}$ Despite their advantages, current lithium conducting solid electrolytes exhibit conductivities of $\sim 1 \times 10^{-2} \mathrm{~S} \mathrm{~cm}^{-1}$, which are still one order of magnitude lower than those of organic liquid electrolytes and therefore limit the feasibility of an all solid-state device. ${ }^{4}$ In recent years, research has centered on lithium conducting garnets as a very promising candidate as a solid electrolyte. ${ }^{5}$ Following the first report by Thangadurai et al. in $2003,{ }^{6}$ the fast $\mathrm{Li}$ conducting garnet $\mathrm{Li}_{5} \mathrm{La}_{3} \mathrm{M}_{2} \mathrm{O}_{12}(\mathrm{M}=\mathrm{Nb}$, Ta) has focused research on this class of materials. ${ }^{5}$ Over the past decade, the research accomplished has provided us with a thorough understanding of the structure-property relationships in this class of materials. However, the necessary improvement of the ionic conductivity to match that of the liquid polymer electrolytes has not been achieved yet. This Perspective article will discuss the overall structure of the garnets and the common approaches employed to improve the conductivity of these materials. The intention is to provide a better understanding of the relationship between the structural parameters of garnets (such as Li composition, occupancy disorder and lattice parameters) and the ionic conductivity. For a complete literature review on garnet solid electrolytes the reader is referred to Thangadurai et $a l .{ }^{5} \mathrm{~A}$ short structural overview in combination with the compiled conduc- 
tivity data of published research efforts will shed light on the structural limitation of this class of materials and hopefully inspire more researchers to focus on exploring novel lithium conducting solid electrolytes.

\section{Crystal structure of lithium "stuffed" garnets}

Lithium-containing garnets $\mathrm{Li}_{x} \mathrm{M}_{2} \mathrm{M}_{3}^{\prime} \mathrm{O}_{12}$ derive from the grossular structural prototype $\mathrm{Ca}_{3} \mathrm{Al}_{2} \mathrm{Si}_{3} \mathrm{O}_{12}$ (Space group Ia $\overline{3} d$ ). ${ }^{7}$ The structure of $\left\{\mathrm{Ca}_{3}\right\}\left[\mathrm{Al}_{2}\right]\left(\mathrm{Si}_{3}\right) \mathrm{O}_{12}$ contains a network of two octahedral $\mathrm{AlO}_{6}$, three antiprismatic $\mathrm{CaO}_{8}$ and three tetrahedral $\mathrm{SiO}_{4}$ polyhedra per unit formula. ${ }^{8-10}$ In the lithium conducting phases, $\mathrm{Li}$ replaces the tetrahedral $\mathrm{Si}^{4+}$, e.g. in $\mathrm{Li}_{3} \mathrm{La}_{3} \mathrm{Te}_{2} \mathrm{O}_{12} \cdot{ }^{11}$ However, for a high ionic conductivity a higher lithium content is needed, which is achieved in the Li"stuffed" garnet compositions." ${ }^{5,7}$ The crystal structure of the initially reported composition $\mathrm{Li}_{5} \mathrm{La}_{3} \mathrm{M}_{2} \mathrm{O}_{12}{ }^{12}$ can be found in Fig. 1(a). These stuffed structures contain more $\mathrm{Li}^{+}$per unit formula than can be placed on the tetrahedral position and the composition may be written as $\mathrm{Li}_{2}\left\{\mathrm{La}_{3}\right\}\left[\mathrm{M}_{2}\right]\left(\mathrm{Li}_{3}\right) \mathrm{O}_{12}$. The excess lithium occupies interstitial pseudo-octahedral sites, sharing faces with the tetrahedral positions (Wyckoff position 24d). ${ }^{7}$ In the interstitial position, the $\mathrm{Li}^{+}$cations can occupy two different crystallographic Wyckoff positions, 96h and $48 \mathrm{~g}$, respectively, as shown in Fig. 1. Neutron diffraction studies on $\mathrm{Li}_{5} \mathrm{La}_{3} \mathrm{Ta}_{2} \mathrm{O}_{12}$ by Cussen et al. ${ }^{13,14}$ have suggested a displacement of the $\mathrm{Li}^{+}$, away from $48 \mathrm{~g}$ towards the Wyckoff position 96h. Electrostatic interactions between the $\mathrm{Li}^{+}$ cations forbid the occupation of an octahedral site that has a $\mathrm{Li}^{+}$-ion on both face-sharing tetrahedral sites, which leads to a predicted theoretical upper limit of $7.5 \mathrm{Li}^{+}$per formula unit. ${ }^{15}$ However, this upper limit requires a half occupancy of the tetrahedral sites with a full occupancy of the octahedral sites and a more practical limit is $x(\mathrm{Li})<7.5$ per formula unit. ${ }^{15}$ Indeed, compositions with $7 \mathrm{Li}^{+}$per formula unit are thermodynamically stable only in a tetragonal unit cell where ordering of the lithium cations occurs and only low ionic conductivities are achieved. ${ }^{16}$ Recent results show that a Li content of 6.5-6.6 Li per formula unit is required to stabilize the cubic phase. ${ }^{17}$

A structural representation of the polyhedra connectivity can be found in Fig. 1(b). While the $\mathrm{TaO}_{6}$ octahedra are basically isolated structural units, all $\mathrm{LaO}_{8}$ polyhedra share an edge with each other and with the $\mathrm{TaO}_{6}$ octahedra. The $\mathrm{Li}-\mathrm{O}$ polyhedra bridge the gap between the different $\mathrm{TaO}_{6}$ octahedra leading to a good connectivity of diffusion pathways in the structure. $^{7}$ Theoretically, different Li-diffusion pathways are possible, in which they either involve the tetrahedral site (Wyckoff 24d) or only the octahedral Li site. For instance, anisotropic thermal displacement parameters obtained via neutron diffraction, and the maximum entropy method suggest the diffusion is via all possible Li sites. ${ }^{19,20}$ However, Li nuclear magnetic resonance and dielectric loss spectroscopy results suggest another underlying diffusion mechanism (see Fig. 2). The mechanism involves immobile tetrahedrally coordinated Li sites (Wyckoff 24d) with the Li-ions hopping between the octahedral sites, bypassing these tetrahedral sites. ${ }^{18,21-25}$ Further experimental results corroborate the octahedral pathway mechanism with static Li cations on the tetrahedral sites. It was found that in $\mathrm{Li}_{7} \mathrm{La}_{3} \mathrm{Zr}_{2} \mathrm{O}_{12}$ impurity ions like $\mathrm{Al}^{3+}$, which are necessary to stabilize the cubic garnet, are located on the tetrahedral $24 \mathrm{~d}$ site. ${ }^{26}$ If the diffusion mechanism involves the tetrahedral sites, a decrease of the ionic conductivity should occur due to blocking by $\mathrm{Al}^{3+}$ ions. However, this is not observed. Indeed, recent work targeted the substitution of $\mathrm{Ga}^{3+}$ on the tetrahedral Li site, and this substitution leads to an increase of the ionic conductivity. The increased (a)



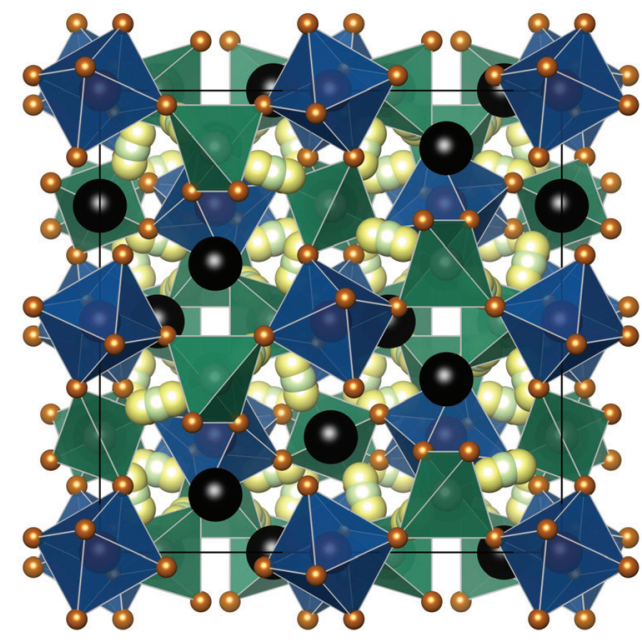

(b)

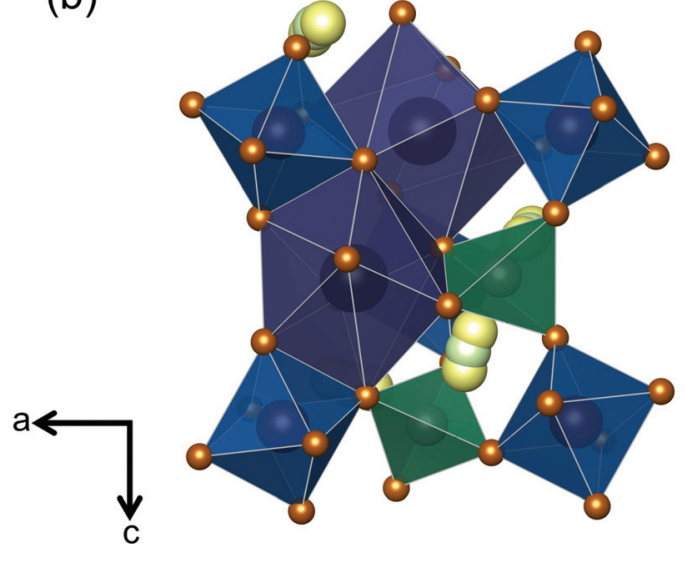

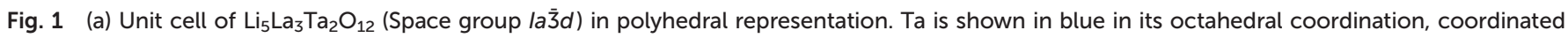



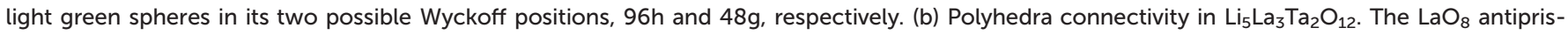

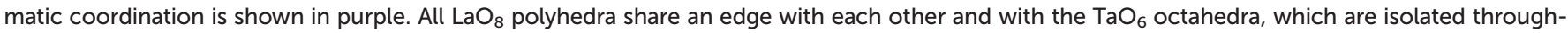
out the structure. The Li-O polyhedra and interstitial positions bridge between the octahedra, leading to a high structural flexibility. 


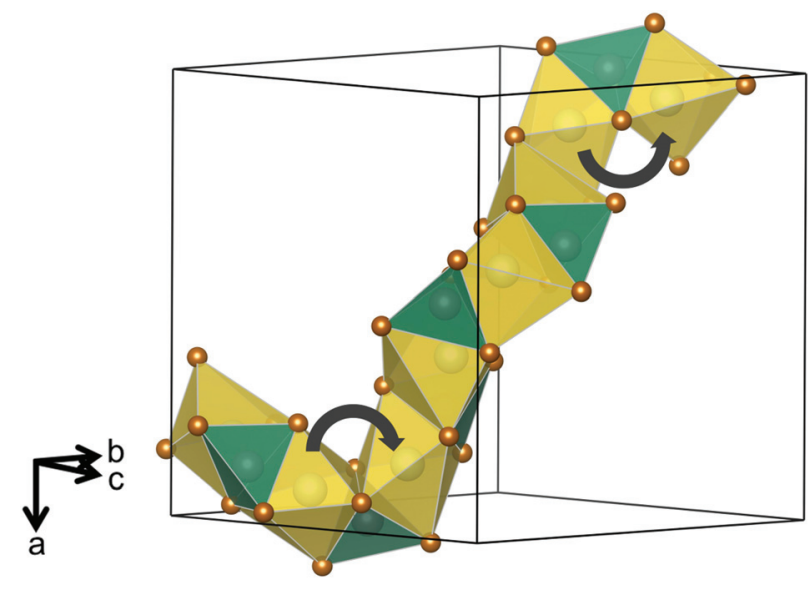

Fig. 2 Connectivity of the $\mathrm{LiO}_{6}$ (yellow) and $\mathrm{LiO}_{4}$ polyhedra (green) along one diagonal chain in the unit cell. All Li-O octahedra share faces with the tetrahedra and an edge with each other along the chains. While the connectivity is three dimensional in the unit cell, a single chain has been chosen for a better representation. The grey arrows indicate the diffusion pathways between the octahedral sites, bypassing the immobile $\mathrm{Li}^{+}$in the tetrahedral sites. ${ }^{18}$ The high disorder of $\mathrm{Li}^{+}$cations and the high diffusion pathway degeneracy in the cubic unit cell lead to high ionic conductivities. Figure adapted from Baral et al. ${ }^{18}$

conductivity is ascribed to the enhanced disorder and $\mathrm{Li}$ content on the mobile octahedral site. ${ }^{27}$

The low occupancy on the different sites and the complex distribution of $\mathrm{Li}^{+}$and vacancies across the different lithium positions leads to a critical ratio between vacancy and site occupancy of lithium; this, in combination with the high diffusion pathway degeneracy of the cubic unit cell, leads to very high ionic conductivities in these compounds. ${ }^{5,7,19}$

\section{Approaches for higher ionic conductivities}

The disorder and tunability in the garnet structure allows for multiple compositions and many options for targeted substitution that can influence the ionic conductivity. In general, researchers have focused on two main approaches to increase the ionic conductivity in a material: through an increase of the $\mathrm{Li}^{+}$concentration or an increase of the mobility of the cations. Commonly, aliovalent substitution is used to increase the $\mathrm{Li}^{+}$ content in order to optimize the ionic performance, for instance in $\mathrm{Li}_{7} \mathrm{La}_{3} \mathrm{Zr}_{2} \mathrm{O}_{12}, \mathrm{Li}_{3+x} \mathrm{Nd}_{3} \mathrm{Te}_{2-x} \mathrm{Sb}_{x} \mathrm{O}_{12}$ and $\mathrm{Li}_{5} \mathrm{La}_{3}(\mathrm{Ta} /$ $\mathrm{Nb})_{2} \mathrm{O}_{12} \cdot{ }^{6,11,19,23,25,26,28-32}$ To maintain a charged balanced material, the Li content has to increase and the lithium ionic conductivities increase concurrently.

Further studies have demonstrated an increase in the $\mathrm{Li}$ content using $\mathrm{Ca}^{2+}, \mathrm{Sr}^{2+}$, and $\mathrm{Ba}^{2+}$ as substituents for $\mathrm{La}^{3+}$ in $\mathrm{Li}_{5} \mathrm{La}_{3} \mathrm{Ta}_{2} \mathrm{O}_{12} \cdot{ }^{14,33-38}$ While this substitution leads to an increased ionic conductivity due to a higher lithium content, the nature of the alkaline earth cations seem to have an effect on the conductivity as well. An increase in the ionic radius of the 8 -fold coordinated site increases the ionic conductivity.
Recently Melot and coworkers have been able to elucidate the underlying structural mechanism for this behavior, employing a combination of neutron and synchrotron diffraction studies. ${ }^{20}$ The increasing ionic radius from $\mathrm{Ca}^{2+}$ over $\mathrm{Sr}^{2+}$ to $\mathrm{Ba}^{2+}$ increases the polyhedron volume of the La position, the site which is also occupied by the alkaline earth cation. While these polyhedra expand (see connectivity representation in Fig. 1(b)), the $\mathrm{TaO}_{6}$ octahedra volumes remain constant due to their isolated nature and the strong $\mathrm{Ta}-\mathrm{O}$ bonding interaction. This induces an expansion of the $\mathrm{Li}-\mathrm{O}$ polyhedra due to chemical pressure on the easily polarizable $\mathrm{Li}-\mathrm{O}$ bond, ultimately leading to broader diffusion pathways and higher ionic conductivities. $^{20}$

\section{Structural limitations}

The research efforts of the past decades have made it possible to understand the underlying structure-to-property relationships in lithium conducting garnets. This knowledge has led to targeted efforts to increase the ionic conductivities in order to obtain competitive ceramics for all solid-state batteries. However, the currently attained room temperature lithium ionic conductivities of $\sim 1 \times 10^{-3} \mathrm{~S} \mathrm{~cm}^{-1}$ in garnets are still below the threshold of the organic liquid electrolytes. Fig. 2 and 3 show the compiled Li ionic conductivities of 100 various compositions against the nominal lithium content and the lattice parameter, using ref. $6,11,18,20,25,28$ and 30-71. In many instances, aliovalent substitution has been employed to increase the Li content for a higher ionic conductivity.

Fig. 3 shows an optimal Li content for the highest conductivity at $x \sim 6.5$, which is below the theoretical limit of 7.5. While this is helpful in knowing which lithium content is necessary for a high conductivity, it simultaneously leads to a

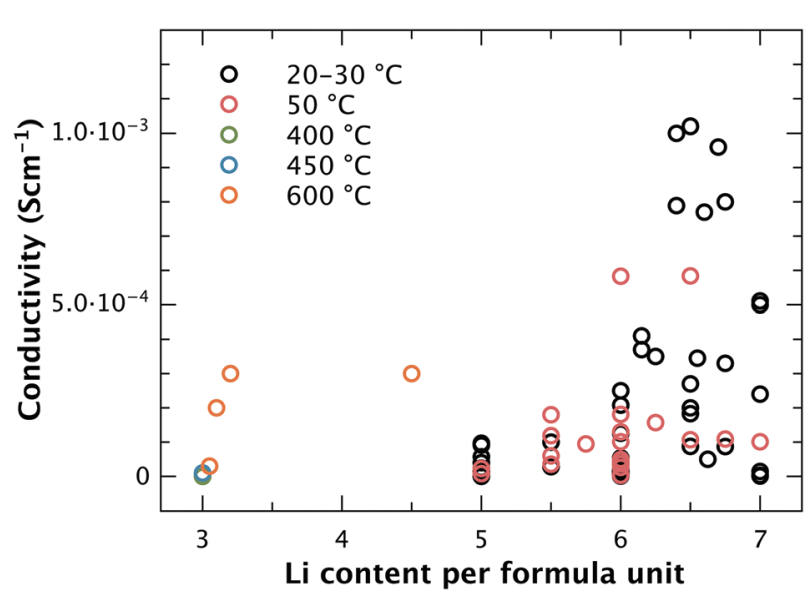

Fig. 3 Lithium ion conductivity vs. nominal Li content in 100 different garnet compositions $\mathrm{Li}_{x} \mathrm{M}_{2} \mathrm{M}_{3} \mathrm{O}_{12}$ showing the maximum obtained conductivity obtained in this class of materials. The highest room temperature lithium ionic conductivities of $\sim 1 \times 10^{-3} \mathrm{~S} \mathrm{~cm}^{-1}$ are obtained around the optimum Li content of $x=6.5$. All data points were obtained from ref. $6,11,18,20,25,28$ and $30-71$, at their lowest measured temperature. 
loss of a degree of freedom in finding new promising compositions in the garnet family.

Melot and coworkers have shown that a control of the unit cell parameters in $\mathrm{Li}_{6} \mathrm{MLa}_{2} \mathrm{Ta}_{2} \mathrm{O}_{12}$ using substitution on the La-site leads to chemical pressure on the Li-O polyhedra pathways and ultimately a change of the $\mathrm{Li}^{+}$mobility. ${ }^{20}$ However, the knowledge of the underlying structural mechanism also demonstrates the limitation of this possibility. On the one hand, a substitution on the Li sites will result in a lower Licontent and a possible disruption of the diffusion pathways, while the substitution on the octahedral $\mathrm{MO}_{6}$ sites might not result in much higher mobilities. The isolated nature of the octahedral sites makes it difficult to assert chemical pressure on the Li-O polyhedra, leading to an optimum lattice parameter a around 12.90-12.95 A (see Fig. 3).

Fig. 3 and 4 illustrate a clustering of the ionic conductivities around an optimum $\mathrm{Li}^{+}$concentration and an optimum lattice parameter, possibly showing a limit of $\sim 1 \times 10^{-3} \mathrm{~S} \mathrm{~cm}^{-1}$ for a maximum achievable lithium ionic conductivity in these materials. The structural limitations and upper limit for the conductivity point out the necessity to find new approaches to obtain higher conductivities in a structurally optimized garnet material. One approach to overcome this problem is the use of thin film solid electrolytes, reducing the separator resistance, which scales with the thickness of the film. ${ }^{72}$ Another possible approach has been shown in recent studies by substitution with $\mathrm{Ga}$ on the site of the $\mathrm{LiO}_{4}$ tetrahedral sites. ${ }^{27,73}$ This increases the disorder of $\mathrm{Li}$ over the different sites without disrupting the diffusion pathways, ultimately increasing the ionic conductivity and possibly opening up new approaches to obtain higher conductivities. ${ }^{27}$ One, however, needs to be very careful in the selection of elements, since a substitution on the octahedral Li-site will result in a blocking of the diffusion pathways. Nevertheless, considering the known structural

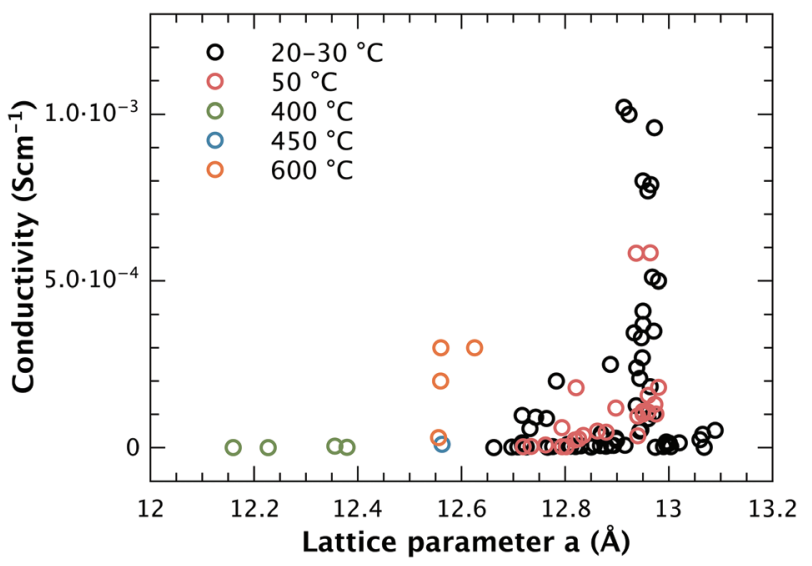

Fig. 4 Lithium ion conductivity vs. room temperature lattice parameter $a$ of 100 different garnet compositions $\mathrm{Li}_{x} \mathrm{M}_{2} \mathrm{M}_{3}^{\prime} \mathrm{O}_{12}$ showing the maximum obtained conductivity obtained in this class of materials. The highest room temperature lithiumionic conductivities of $\sim 1 \times 10^{-3} \mathrm{~S} \mathrm{~cm}^{-1}$ cluster around a very narrow range of optimal lattice constants, with a around 12.90-12.95 $\AA$. All data points were obtained from ref. 6, 11, 18, $20,25,28$ and $30-71$ at their lowest measured temperature. instability of these compounds to humidity and air, which lowers the ionic conductivity significantly, ${ }^{74-76}$ it seems difficult to obtain the necessary ionic conductivity using the current approaches. However, there is a wide variety of promising materials systems such as glassy materials, glass ceramics, Li rich anti-perovskites and sulfide superionic conductors (e.g. such as $\mathrm{Li}_{3} \mathrm{PS}_{4}$ and $\left.\mathrm{Li}_{10} \mathrm{SnP}_{2} \mathrm{~S}_{14}\right)$ available, where targeted structural chemistry might lead to the desired properties. ${ }^{4,77-84}$

\section{Conclusion}

In summary, this Perspective article provides a short overview over the research findings on the structure-to-property relationships in Li-conducting garnets in the past decade. An examination and compilation of published ionic conductivities, Licontent and structural data shows that an optimized limit has possibly been reached in the quest to achieve an even higher ionic conductivity in the class of fast-ion conducting garnets. Yet, inorganic ceramics currently offer the most promising combination for the next generation Li-ion battery. Therefore, it is necessary to find different approaches (e.g. enhancing structural disorder) and novel materials that exhibit a suitable combination of stability and ionic conductivity for application in all-solid-state batteries.

\section{References}

1 J. B. Goodenough and K.-S. Park, J. Am. Chem. Soc., 2013, 135, 1167-1176.

2 J.-M. Tarascon and M. Armand, Nature, 2001, 414, 359-367. 3 Y. Shao, F. Ding, J. Xiao, J. Zhang, W. Xu, S. Park, J.-G. Zhang, Y. Wang and J. Liu, Adv. Funct. Mater., 2013, 23, 987-1004.

4 N. Kamaya, K. Homma, Y. Yamakawa, M. Hirayama, R. Kanno, M. Yonemura, T. Kamiyama, Y. Kato, S. Hama, K. Kawamoto and A. Mitsui, Nat. Mater., 2011, 10, 682-686.

5 V. Thangadurai, S. Narayanan and D. Pinzaru, Chem. Soc. Rev., 2014, 43, 4714-4727.

6 V. Thangadurai, H. Kaack and W. Weppner, J. Am. Ceram. Soc., 2003, 86, 437.

7 E. J. Cussen, J. Mater. Chem., 2010, 20, 5167-5173.

8 G. Menzer, Z. Kristallogr., 1926, 63, 157-158.

9 G. Menzer, Z. Kristallogr., 1928, 69, 300-396.

10 S. Geller, Z. Kristallogr., 1967, 125, 1-47.

11 E. J. Cussen, T. W. S. Yip, G. O’Neill and M. P. O'Callaghan, J. Solid State Chem., 2011, 184, 470-475.

12 H. Hyooma and K. Hayashi, Mater. Res. Bull., 1988, 23, 1399-1407.

13 E. J. Cussen, Chem. Commun., 2006, 412-413.

14 M. P. O’Callaghan and E. J. Cussen, Chem. Commun., 2007, 2048-2050.

15 H. Xie, J. A. Alonso, Y. Li, M. T. Fern and J. B. Goodenough, Chem. Mater., 2011, 23, 3587-3589. 
16 A. Logéat, T. Köhler, U. Eisele, B. Stiaszny, A. Harzer, M. Tovar, A. Senyshyn, H. Ehrenberg and B. Kozinsky, Solid State Ionics, 2012, 206, 33-38.

17 T. Thompson, J. Wolfenstine, J. L. Allen, M. Johannes, A. Huq, I. N. David and J. Sakamoto, J. Mater. Chem. A, 2014, 2, 13431-13436.

18 A. K. Baral, S. Narayanan, F. Ramezanipour and V. Thangadurai, Phys. Chem. Chem. Phys., 2014, 16, 1135611365.

19 J. Han, J. Zhu, Y. Li, X. Yu, S. Wang, G. Wu, H. Xie, S. C. Vogel, F. Izumi, K. Momma, Y. Kawamura, Y. Huang, J. B. Goodenough and Y. Zhao, Chem. Commun., 2012, 48, 9840-9842.

20 W. G. Zeier, S. Zhou, B. Lopez-Bermudez, K. Page and B. C. Melot, ACS Appl. Mater. Interfaces, 2014, 6, 1090010907.

21 L. van Wüllen, T. Echelmeyer, H.-W. Meyer and D. Wilmer, Phys. Chem. Chem. Phys., 2007, 9, 3298-3303.

22 B. Koch and M. Vogel, Solid State Nucl. Magn. Reson., 2008, 34, 37-43.

23 M. Nyman, T. M. Alam, S. K. McIntyre, G. C. Bleier and D. Ingersoll, Chem. Mater., 2010, 22, 5401-5410.

24 A. Kuhn, S. Narayanan, L. Spencer, G. Goward, V. Thangadurai and M. Wilkening, Phys. Rev. B: Condens. Matter, 2011, 83, 094302.

25 S. Narayanan, F. Ramezanipour and V. Thangadurai, J. Phys. Chem. C, 2012, 116, 20154-20162.

26 H. Buschmann, J. Dölle, S. Berendts, A. Kuhn, P. Bottke, M. Wilkening, P. Heitjans, A. Senyshyn, H. Ehrenberg, A. Lotnyk, V. Duppel, L. Kienle and J. Janek, Phys. Chem. Chem. Phys., 2011, 13, 19378-19392.

27 C. Bernuy-Lopez, W. Manalastas, J. Miguel Lopez del Amo, A. Aguadero, F. Aguesse and J. A. Kilner, Chem. Mater., 2014, 26, 3610-3617.

28 R. Murugan, V. Thangadurai and W. Weppner, Angew. Chem., Int. Ed., 2007, 46, 7778-8771.

29 E. Rangasamy, J. Wolfenstine and J. Sakamoto, Solid State Ionics, 2012, 206, 28-32.

30 M. P. O'Callaghan, A. S. Powell, J. J. Titman, G. Z. Chen and E. J. Cussen, Chem. Mater., 2008, 15, 2360-2369.

31 Y.-X. Gao, X. P. Wang, W. G. Wang, Z. Zhuang, D. M. Zhang and Q. Fang, Solid State Ionics, 2010, 181, 1415-1419.

32 C. R. Mariappan, K. I. Gnanasekar, V. Jayaraman and T. Gnanasekaran, J. Electroceram., 2013, 30, 258-265.

33 J. Awaka, N. Kijima, Y. Takahashi, H. Hayakawa and J. Akimoto, Solid State Ionics, 2009, 180, 602-606.

34 V. Thangadurai and W. Weppner, Adv. Funct. Mater., 2005, 15, 107-112.

35 R. Murugan, W. Weppner, P. Schmid-Beurmann and V. Thangadurai, Mater. Sci. Eng., B, 2007, 143, 14-20.

36 R. Murugan, V. Thangadurai and W. Weppner, Appl. Phys. A, 2008, 91, 615-620.

37 V. Thangadurai and W. Weppner, J. Am. Ceram. Soc., 2005, 88, 411-418.

38 A. Ramzy and V. Thangadurai, ACS Appl. Mater. Interfaces, 2010, 2, 385-390.
39 S. Narayanan, V. Epp, M. Wilkening and V. Thangadurai, RSC Adv., 2012, 2, 2553-2561.

40 E. J. Cussen and T. W. S. Yip, J. Solid State Chem., 2007, 180, 1832-1839.

41 R. Murugan, V. Thangadurai and W. Weppner, J. Electrochem. Soc., 2008, 155, A90-A101.

42 R. Murugan, W. Weppner, P. Schmid-Beurmann and V. Thangadurai, Mater. Res. Bull., 2008, 43, 2579-2591.

43 M. P. O’Callaghan, D. R. Lynham, E. J. Cussen and G. Z. Chen, Chem. Mater., 2006, 16, 4681-4689.

44 I. P. Roof, M. D. Smith, E. J. Cussen and H.-C. zur Loye, J. Solid State Chem., 2009, 182, 295-300.

45 V. Thangadurai and W. Weppner, J. Solid State Chem., 2006, 179, 974-984.

46 H. Xie, Y. Li, J. Han, Y. Dong, M. P. Paranthaman, L. Wang, M. Xu, A. Gupta, Z. Bi, C. A. Bridges, M. Nakanishui, A. P. Sokolov and J. B. Goodenough, J. Electrochem. Soc., 2012, 159, A1148-A1151.

47 H. Peng, Q. Wu and L. Xiao, J. Sol-Gel Sci. Technol., 2013, 66, 175-179.

48 J. Percival, E. Kendrick and P. R. Slater, Mater. Res. Bull., 2008, 43, 765-770.

49 J. L. Allen, J. Wolfenstine, E. Rangasamy and J. Sakamoto, J. Power Sources, 2012, 206, 315-319.

50 L. Dhivya, N. Janani, B. Palanivel and R. Murugan, AIP Adv., 2013, 3, 082115.

51 M. A. Howard, O. Clemens, E. Kendrick, K. S. Knight, D. C. Apperly, P. A. Anderson and P. R. Slater, Dalton Trans., 2012, 41, 12048-12053.

52 I. Kokal, K. V. Ramanujachary, P. H. L. Notten and H. T. Hintzen, Mater. Res. Bull., 2012, 47, 1932-1935.

53 M. Kotobuki and K. Kanamura, Ceram. Interfaces, 2013, 39, 6481-6487.

54 Y. Li, J. Han, C. Wang, H. Xie and J. B. Goodenough, J. Mater. Chem., 2012, 22, 15357-15361.

55 Y. Li, C. Wang, H. Xie, J. Cheng and J. B. Goodenough, Electrochem. Commun., 2011, 13, 1289-1292.

56 S. Narayanan and V. Thangadurai, J. Power Sources, 2011, 196, 8085-8090.

57 J. Wolfenstine, J. Ratchford, E. Rangasamy, J. Sakamoto and J. L. Allen, Mater. Chem. Phys., 2012, 22, 571-575.

58 Y. Zhong, Q. Zhou, Y. Guo, Z. Li and Y. Qiang, Ionics, 2013, 19, 697-700.

59 C. Deviannapoorani, L. Dhivya, S. Ramakumar and R. Murugan, J. Power Sources, 2013, 240, 18-25.

60 A. Gupta, R. Murugan, M. P. Paranthaman, Z. Bi, C. A. Bridges, M. Nakanishui, A. P. Skolov, K. S. Han, E. W. Hagaman, H. Xie, C. B. Mullins and J. B. Goodenough, J. Power Sources, 2012, 209, 184-188.

61 S. Ramakumar, L. Satyanarayana, S. V. Manorama and R. Murugan, Phys. Chem. Chem. Phys., 2013, 15, 1132711338.

62 H. Buschmann, S. Berendts, B. Mogwitz and J. Janek, J. Power Sources, 2012, 206, 236-244.

63 Y. Wang and W. Lai, Electrochem. Solid-State Lett., 2012, 15, A68-A71. 
64 S. Ohta, T. Kobayashi and T. Asaoka, J. Power Sources, 2011, 196, 3342-3345.

65 H. Xie, Y. Li and J. B. Goodenough, Mater. Res. Bull., 2012, 47, 1229-1232.

66 W. G. Wang, X. P. Wang, Y.-X. Gao and Q. Fang, Solid State Ionics, 2009, 180, 1251-1256.

67 A. Dumon, M. Huang, Y. Shen and C. Nan, Solid State Ionics, 2013, 233, 102-106.

68 E. Rangasamy, J. Wolfenstine, J. L. Allen and J. Sakamoto, J. Power Sources, 2013, 230, 261-266.

69 T. Zaiss, M. Ortner, R. Murugan and W. Weppner, Ionics, 2010, 16, 855-858.

70 R. Murugan, S. Ramakumar and N. Janani, Electrochem. Commun., 2011, 13, 1373-1375.

71 G. T. Hitz, E. D. Wachsman and V. Thangadurai, J. Electrochem. Soc., 2013, 160, A1248-A1255.

72 M. J. Mees, G. Pourtois, F. Rosciano, B. Put, P. M. Vereecken and A. Stesmans, Phys. Chem. Chem. Phys., 2014, 16, 5399-5406.

73 H. El Shinawi and J. Janek, J. Power Sources, 2013, 225, 13-19.

74 C. Galven and J.-1. Fourquet, Chem. Mater., 2011, 23, 18921900.
75 G. Larraz, A. Orera and M. L. Sanjuán, J. Mater. Chem. A, 2013, 1, 11419-11428.

76 Y. Li, Z. Wang, C. Li, Y. Cao and X. Guo, J. Power Sources, 2014, 248, 642-646.

77 S. Kondo, K. Takada and Y. Yamamura, Solid State Ionics, 1992, 53, 1183-1186.

78 K. Takada, N. Aotani and S. Kondo, J. Power Sources, 1993, 43, 135-141.

79 Y. Zhao and L. L. Daemen, J. Am. Chem. Soc., 2012, 134, 15042-15047.

80 Z. Liu, W. Fu, E. A. Payzant, X. Yu, Z. Wu, N. J. Dudney, J. Kiggans, K. Hong, A. J. Rondinone and C. Liang, J. Am. Chem. Soc., 2013, 135, 975-978.

81 F. Mizuno, A. Hayashi, K. Tadanaga and M. Tatsumisago, Adv. Mater., 2005, 17, 918-921.

82 P. Bron, S. Johansson, K. Zick, J. Schmedt auf der Günne, S. Dehnen and B. Roling, J. Am. Chem. Soc., 2013, 135, 15694-15697.

83 A. Hayashi, K. Minami, F. Mizuno and M. Tatsumisago, J. Mater. Sci., 2008, 43, 1885-1889.

84 R. Kanno and M. Maruyama, J. Electrochem. Soc., 2001, 148, A742-A746. 